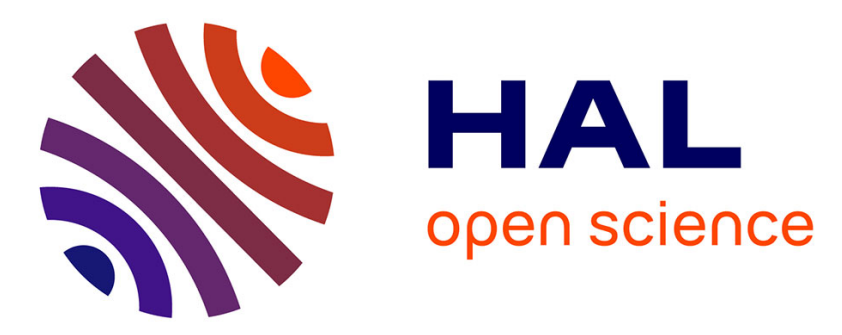

\title{
Thoughts on the ideal behavior of mixed micelles and the appropriate application of regular solution theory (RST).
}

Pierre Letellier, Alain Mayaffre, Mireille Turmine

\section{To cite this version:}

Pierre Letellier, Alain Mayaffre, Mireille Turmine. Thoughts on the ideal behavior of mixed micelles and the appropriate application of regular solution theory (RST).. Journal of Colloid and Interface Science, 2011, 354 (1), pp.248-255. 10.1016/j.jcis.2010.09.082 . hal-00602669

\section{HAL Id: hal-00602669 \\ https://hal.sorbonne-universite.fr/hal-00602669}

Submitted on 14 Apr 2015

HAL is a multi-disciplinary open access archive for the deposit and dissemination of scientific research documents, whether they are published or not. The documents may come from teaching and research institutions in France or abroad, or from public or private research centers.
L'archive ouverte pluridisciplinaire HAL, est destinée au dépôt et à la diffusion de documents scientifiques de niveau recherche, publiés ou non, émanant des établissements d'enseignement et de recherche français ou étrangers, des laboratoires publics ou privés. 


\title{
Thoughts on the ideal behaviour of mixed micelles and the appropriate application of Regular Solution Theory (RST)
}

\author{
Pierre Letellier, Alain Mayaffre, Mireille Turmine* \\ Laboratoire Interfaces et Systèmes Electrochimiques, CNRS, UPR15-LISE; \\ Université Pierre et Marie Curie-Paris6, Case 133, \\ 4 place Jussieu, 75252 Paris Cedex 05, France.
}

e-mail: mireille.turmine@upmc.fr

\begin{abstract}
Solutions of mixed surfactants are often considered as solvent mixtures. Usually, mixed micellar aggregates are considered as a homogeneous mixture of solvents dispersed in a solution. But the transposition of the usual thermodynamic models of solvent mixtures to mixed micelles is not always so obvious. We discussed this point in this paper by considering several cases of surfactant mixtures. One of the major problems is to define the molar fraction of each surfactant in the aggregate especially when a charged surfactant is employed in the mixture, because possible dissociation of the components of the mixture has to be considered in the bulk as well in micelle. This definition is crucial especially for the characterization of the ideal behavior which is usually described by the Clint relation, as well for the application of Regular Solution Theory (RST) which is most frequently applied model to interpret the behaviour of surfactant mixtures. We showed in this paper how the definition of the molar fraction can change the equations and the interpretations.
\end{abstract}

Keywords: surfactant, mixed micelle, thermodynamics, behaviour model 


\section{Introduction}

The use of surfactant mixtures permits control over the properties of the micellar solutions over a wide range for optimization of applications such as in cosmetics, biology, pharmacology, etc. The literature is teeming with works describing the behaviour of these systems which may include charged or neutral surfactants, polymers, etc. Many publications also try to interpret the behaviour observed for these mixtures using the thermodynamic laws. The most popular way consists in considering the mixed micellar aggregate as a homogeneous mixture of solvents dispersed within the solution with which it is in equilibrium. At first sight, this approach appears to be appropriate because it makes use of the extensive and well understood work on thermodynamics of solvent mixtures [1].

This transposition is not always obvious for various reasons.

The first is that, contrary to mixed solvents, the composition of the micellar phase is not a controllable variable. Its value is fixed by the partition equilibria of the species between the aggregate and the surrounding medium. Only the total composition of the micellar solution is accessible to the experimenter. The composition of mixed micelle must be experimentally determined [2] or calculated. We introduced simple solutions to reach it without using a modeling of the physicochemical properties of the system, a priori [3].

The second is that the transposition of the relations characterizing the solvent mixtures to mixed micelles is not always straightforward, in particular when the definition of the behaviour model (as the ideality) for the mixtures of ionic and nonionic surfactants is concerned. This major difficulty did not greatly draw researchers' attention although it directly relates to the utilization of Regular Solution Theory (RST) [4], amply used to interpret the behaviours of these mixtures. 
We propose in this article to review this subject and to show that, in many situations, the systematic use of the relation of ideality introduced by Clint [5] is unsuited. The consequence of this is that the analysis of the experimental results by the RST is also inappropriate.

For the sake of clarity, it seemed important to us to expose and comment step by step the reasoning of thermodynamics of solutions we used, even if they are classical.

\section{The micellar solution considered as solvent mixture}

Consider a mixture made of $n_{1}$ moles of water, $n_{2}$ moles of surfactant 2 (charged or not) and of $n_{3}$ moles of surfactant 3 (charged or not). The free energy of this mixture is

$\mathrm{G}=\mathrm{n}_{1} \mu_{1}+\mathrm{n}_{2} \mu_{2}+\mathrm{n}_{3} \mu_{3}$

where $\mu_{1}, \mu_{2}, \mu_{3}$ are the chemical potentials of the system components (aggregated or not).

Conventionally, the micellar aggregate is represented as a "pseudo-phase" and contents are attributed to it. In fact, the micellar aggregate is a "non-autonomous phase" as defined by Defay [6] since its constitution depends on the composition of its environment and cannot be freely fixed by the experimenter. In this case, we will suppose that the micellar pseudo phase is constituted by $\mathrm{n}_{2}^{\mathrm{m}}$ of 2 and $\mathrm{n}_{3}^{\mathrm{m}}$ of 3 and that water does not participate in the aggregate constitution.

If the surfactants are charged, this separation implies that the pseudo-phase is electrically neutral.

$\mathrm{n}_{2}=\mathrm{n}_{2}^{\mathrm{m}}+\mathrm{n}_{2}^{\mathrm{b}}$

$\mathrm{n}_{3}=\mathrm{n}_{3}^{\mathrm{m}}+\mathrm{n}_{3}^{\mathrm{b}}$

$\mathrm{n}_{2}^{\mathrm{b}}$ and $\mathrm{n}_{3}^{\mathrm{b}}$ are the quantities of 2 and 3 in the bulk.

The free energy of the micellar pseudo-phase is then

$\mathrm{G}_{(\mathrm{m})}=\mathrm{n}_{2}^{\mathrm{m}} \mu_{2}+\mathrm{n}_{3}^{\mathrm{m}} \mu_{3}$ 
The micellar system is defined by its contents $\left(\mathrm{n}_{2}^{\mathrm{m}}\right.$ and $\left.\mathrm{n}_{3}^{\mathrm{m}}\right)$, whatever the shape adopted by the constituents, whether they are dissociated or not. This segregation of the components is purely conventional, and other conventions could be obviously considered.

In a recent paper [7], we thus proposed to compare the aggregates made of charged surfactants to systems with ill-defined geometry, separated from their environment by "fuzzy interfaces" and which follow the relations of nonextensive thermodynamics [8]. One must have in mind that the "pseudo-phase" model is a conceptual choice, that it is not unique and that it does not correspond to an obligation imposed by the physical reality of the system. Other approaches of these systems are based on the molecular theories which permit to describe the mixtures' behaviours with an excellent precision [9-15].

Below the aggregation threshold, the chemical potentials are classically expressed according to the various species concentrations in solution, by taking generally as reference the model of infinitely dilute solutions. Beyond the aggregation threshold, their expression must be specified.

\subsection{Activities of the components of the micelle}

Temperature and pressure are fixed. Let suppose that the surfactants in the pseudo-phase are in equilibrium with the species in solution, which implies that they have same chemical potentials. Let consider first the case of pure surfactants. By convention, we will write at the aggregation threshold, the surfactant chemical potentials as

$$
\begin{aligned}
& \mu_{2}=\mu_{2}^{\mathrm{m}}=\mu_{2}^{\mathrm{b}, \infty}+\mathrm{RT} \ln \mathrm{a}_{2}^{\mathrm{b}, \mathrm{o}} \\
& \mu_{3}=\mu_{3}^{\mathrm{m}}=\mu_{3}^{\mathrm{b}, \infty}+\mathrm{RT} \ln \mathrm{a}_{3}^{\mathrm{b}, \mathrm{o}}
\end{aligned}
$$

$\mu_{2}^{\mathrm{m}}$ and $\mu_{3}^{\mathrm{m}}$ are the chemical potentials of the pure micellar phases of the two components.

$\mu_{2}^{\mathrm{b}, \infty}$ and $\mu_{3}^{\mathrm{b}, \infty}$ are the standard chemical potentials of 2 and 3 at infinite dilution in the bulk, in 
the scale (molarity, molality or molar fraction) chosen to express the concentration of the species. $\mathrm{a}_{2}^{\mathrm{b}, \mathrm{o}}$ and $\mathrm{a}_{3}^{\mathrm{b}, \mathrm{o}}$ are the activities of 2 and 3 in the bulk, referred to the infinitely dilute solution at the aggregation threshold, in the same scale of composition.

When surfactants are mixed, above the aggregation threshold, a mixed pseudo-phase is created which is considered to be a solvent mixture. The chemical potentials of 2 and 3 are

$$
\begin{aligned}
& \mu_{2}=\mu_{2}^{\mathrm{m}}+\mathrm{RT} \ln \mathrm{a}_{2}^{\mathrm{m}}=\mu_{2}^{\mathrm{b}, \infty}+\mathrm{RT} \ln \mathrm{a}_{2}^{\mathrm{b}} \\
& \mu_{3}=\mu_{3}^{\mathrm{m}}+\mathrm{RT} \ln \mathrm{a}_{3}^{\mathrm{m}}=\mu_{3}^{\mathrm{b}, \infty}+\mathrm{RT} \ln \mathrm{a}_{3}^{\mathrm{b}}
\end{aligned}
$$

$\mathrm{a}_{2}^{\mathrm{m}}$ and $\mathrm{a}_{3}^{\mathrm{m}}$ are the surfactant activities in the pseudo-phase referred to pure component as the standard state (scale of molar fractions), $\mathrm{a}_{2}^{\mathrm{b}}$ and $\mathrm{a}_{3}^{\mathrm{b}}$ are the activities of 2 and 3 in the bulk referred to the infinitely dilute solution.

It is noteworthy that the activities of the two constituents in the micelle are introduced without referring to a particular model of behaviour for the mixture.

The only imposed condition is that, when the components are sole in solution, their activity is identified with their molar fraction which is unit.

Bringing eq. 4 and 5 together, the relations between the activities in solution referred to the infinitely dilute state and the activities in micelle referred to the pure substance are established.

$$
\begin{aligned}
& a_{2}^{m}=\frac{a_{2}^{b}}{a_{2}^{b, o}} \\
& a_{3}^{m}=\frac{a_{3}^{b}}{a_{3}^{b, o}}
\end{aligned}
$$

Thus, the activities of the micelle components, referred to the pure substance, can be determined knowing the species concentrations at the aggregation threshold. In order to calculate it, we will note $\alpha_{2}$, the proportion of 2 in the solution, such as 
$\alpha_{2}=\frac{\mathrm{n}_{2}}{\mathrm{n}_{2}+\mathrm{n}_{3}}$

Suppose that the surfactant mixture aggregates at the total surfactant $(2+3)$ concentration (cmc). Concentrations of both surfactants, $\mathrm{cmc}_{2}$ and $\mathrm{cmc}_{3}$, at this point, are expressed as $\mathrm{cmc}_{2}=\alpha_{2} \mathrm{cmc}$

$\mathrm{cmc}_{3}=\left(1-\alpha_{2}\right) \mathrm{cmc}$

The critical micellar concentration of the mixture is measured by various experimental techniques, $\alpha_{2}$ is chosen by the experimenter. These variables of the system are relevant. We will consider, hereafter, two simple cases of surfactant mixtures.

\subsection{The surfactant 2 is neutral}

In the case of non-ionic surfactant, 2 for example, the previous relations lead to

$\mathrm{a}_{2}^{\mathrm{m}}=\frac{\mathrm{a}_{2}^{\mathrm{b}}}{\mathrm{a}_{2}^{\mathrm{b}, \mathrm{o}}}=\frac{\mathrm{cmc}_{2} \gamma_{2}}{\mathrm{cmc}_{2}^{\mathrm{o}} \gamma_{2}^{\mathrm{o}}}=\mathrm{cmc} \frac{\alpha_{2}}{\mathrm{cmc}_{2}^{\mathrm{o}}} \frac{\gamma_{2}}{\gamma_{2}^{\mathrm{o}}}$

$\gamma_{2}^{\mathrm{o}}$ and $\gamma_{2}$ are the activity coefficients of 2 in the bulk, for 2 pure and 2 in mixture at the threshold of aggregation, respectively, referred to the infinitely dilute behaviour of 2 . When the solutions are diluted, the values of the activity coefficients of these molecular species can be supposed equal to one. The value of $\mathrm{a}_{2}$ in the mixture is determined by

$\mathrm{a}_{2}^{\mathrm{m}} \approx \frac{\mathrm{cmc}_{2}}{\mathrm{cmc}_{2}^{\mathrm{o}}}=\mathrm{cmc} \frac{\alpha_{2}}{\mathrm{cmc}_{2}^{\mathrm{o}}}$

\subsection{The surfactant 3 is charged}

We will take as example the simple case of a 1-1electrolyte $\left(\mathrm{M}^{+}, \mathrm{X}^{-}\right)$which will be identified with component 3 . The activity of MX in the bulk at the concentration of aggregation, cmc, is given by 
$\mathrm{a}_{3}^{\mathrm{b}}=\mathrm{a}_{\mathrm{M}^{+}}^{\mathrm{b}} \mathrm{a}_{\mathrm{X}^{-}}^{\mathrm{b}}=\left(\mathrm{cmc}_{3} \gamma_{ \pm}\right)^{2}$

$\gamma_{ \pm}$is the mean activity coefficient of the charged surfactant. Writing of these same relations for the micellization of pure surfactant 3 at the critical micellar concentration $\left(\mathrm{cmc}_{3}^{\circ}\right)$ gives

$\mathrm{a}_{3}^{\mathrm{m}}=\frac{\mathrm{a}_{3}^{\mathrm{b}}}{\mathrm{a}_{3}^{\mathrm{b}, \mathrm{o}}}=\left(\frac{\mathrm{cmc}_{3} \gamma_{ \pm}}{\mathrm{cmc}_{3}^{\mathrm{o}} \gamma_{ \pm}^{\mathrm{o}}}\right)^{2} \approx\left(\mathrm{cmc} \frac{1-\alpha_{2}}{\mathrm{cmc}_{3}^{\mathrm{o}}}\right)^{2}$

$\gamma_{ \pm}^{0}$ is the mean activity coefficient of the electrolyte at the critical micellar concentration of pure surfactant $3, \mathrm{cmc}_{3}^{\mathrm{o}}$. The values of the mean activity coefficients can be calculated according to the Debye and Hückel model or, for higher critical micellar concentrations, using the Guntelberg relation (for ionic strength lower than 0.1) [16]. Activity coefficients intervene in eq. 12 as a ratio, and their contribution is generally negligible.

It should be noted that in many work in the literature concerning the mixtures of charged and non-charged surfactants, the calculation of the activity of ionic surfactant is erroneous, the ratio of the critical micellar concentrations was not squared.

When the solution contains an electrolyte with a counterion common to the surfactant, at high concentration (much higher than the $\mathrm{cmc}$ ) the counterion activities at the thresholds of surfactant aggregation, whether pure or in a mixture, are identical. In this case, the activity coefficient of the amphiphile in the bulk is fixed by the added electrolyte. The activity of surfactant 3 is consequently equal to $\mathrm{cmc}_{3} / \mathrm{cmc}_{3}^{\circ}$ if the activity coefficients are neglected. Since the values of the aggregation thresholds are determined for various compositions of the solution, the values of $\mathrm{a}_{2}^{\mathrm{m}}$ and $\mathrm{a}_{3}^{\mathrm{m}}$ are known. The stoichiometric composition of the micelle $\left(\mathrm{x}_{2}\right.$ and $\mathrm{x}_{3}$ ) can be then calculated by exploiting the consequences of the Gibbs-Duhem relation applied to the mixed pseudo-phase, at constant $\mathrm{T}$ and $\mathrm{P}$ [7]

$\mathrm{d} \ln \mathrm{a}_{3}^{\mathrm{m}}=-\frac{\mathrm{x}_{2}}{1-\mathrm{x}_{2}} \mathrm{~d} \ln \mathrm{a}_{2}^{\mathrm{m}}$ 
with

$\mathrm{x}_{2}=\frac{\mathrm{n}_{2}^{\mathrm{m}}}{\mathrm{n}_{2}^{\mathrm{m}}+\mathrm{n}_{3}^{\mathrm{m}}}$

$\mathrm{x}_{3}=\frac{\mathrm{n}_{3}^{\mathrm{m}}}{\mathrm{n}_{2}^{\mathrm{m}}+\mathrm{n}_{3}^{\mathrm{m}}}$

Knowing the pseudo-phase composition and the activities of the components, we can envisage adapting the models of behaviour proposed for solvent mixtures to the mixed micellar pseudophases, in particular, the ideal behaviour.

\section{The ideal behaviour for surfactant mixtures}

As for the solvent mixtures, we will suppose that the ideal behaviour for a surfactant mixture implies a random distribution of the components in the pseudo-phase. The molar entropy of mixture is then given by

$$
\Delta_{\text {mel }} \mathrm{S}_{\mathrm{mol}}=\frac{\mathrm{S}_{\mathrm{mel}}-\mathrm{S}_{\text {initial }}}{\sum \mathrm{n}_{\mathrm{i}}}=-\mathrm{R} \sum \mathrm{x}_{\mathrm{i}} \ln \mathrm{x}_{\mathrm{i}}
$$

$\mathrm{x}_{\mathrm{i}}$ is the molar fraction of the component $\mathrm{i}$ in the mixture. $\mathrm{S}_{\mathrm{mel}}$ is the total entropy of the mixture and $\mathrm{S}_{\text {initial }}$ is the sum of the entropies of each component before the mixing.

This first condition requires that the species which constitute the system have to be clearly identified. While for a mixture of molecules this condition can appear simple, the problem becomes singularly complicated when charged surfactant (susceptible to dissociate) is considered. In the usual picture of charged micelles, in which the amphiphiles constitute the core of the micelle and the counterions are placed outside (in diffuse layers), the problem of the enumeration of the species to be taken into account in eq. 15 becomes obvious [17]. Many studies showed that the degree of association of counterions to micelle depends on its composition [18]. In addition, it should be recalled on this point that the division made to define the contents of the pseudo-phase requires that the mixture remains homogeneous and 
electrically neutral. The second condition to have an ideal behaviour is that the molar enthalpy of mixture is null, $\Delta_{\text {mel }} \mathrm{H}_{\text {mol }}=0$. In the conditions of ideality, the chemical potentials of components $i$ of the micellar mixture are written as follow

$\mu_{\mathrm{i}}=\mu_{\mathrm{i}}^{\mathrm{m}}+\mathrm{RT} \ln \mathrm{x}_{\mathrm{i}}$

The activities of the species are equal to their molar fractions.

\subsection{The ideality for the surfactant mixtures}

We will consider the condition of ideality for several types of mixtures.

\subsubsection{Mixtures of uncharged surfactants}

In the ideal conditions, the activities of 2 and 3 are identified with their stoichiometric molar fractions $\mathrm{x}_{2}$ and $\mathrm{x}_{3}$. The condition of ideality is written as

$$
1=\mathrm{x}_{2}+\mathrm{x}_{3}=\mathrm{a}_{2}^{\mathrm{m}}+\mathrm{a}_{3}^{\mathrm{m}}=\operatorname{cmc}\left(\frac{\alpha_{2}}{\mathrm{cmc}_{2}^{\mathrm{o}}}+\frac{1-\alpha_{2}}{\mathrm{cmc}_{3}^{\mathrm{o}}}\right)
$$

The relation suggested by Clint [5] is then recovered

$$
\frac{1}{\mathrm{cmc}}=\frac{\alpha_{2}}{\mathrm{cmc}_{2}^{\mathrm{o}}}+\frac{1-\alpha_{2}}{\mathrm{cmc}_{3}^{\mathrm{o}}}
$$

The variations of the « critical micellar concentration of mixture », $\Delta \theta_{\text {cmc }}$, with $\alpha_{2}$ are plotted on figure 1 for various values of $\mathrm{cmc}^{\circ}$ of the two surfactants. This magnitude is defined as the difference between the ideal critical micellar concentration (defined in eq. 17) and the concentration corresponding to a linear variation of the cmc with $\alpha_{2}$,

$$
\Delta \theta_{\mathrm{cmc}}=\mathrm{cmc}-\alpha_{2} \mathrm{cmc}_{2}^{\mathrm{o}}-\left(1-\alpha_{2}\right) \mathrm{cmc}_{3}^{\mathrm{o}}
$$




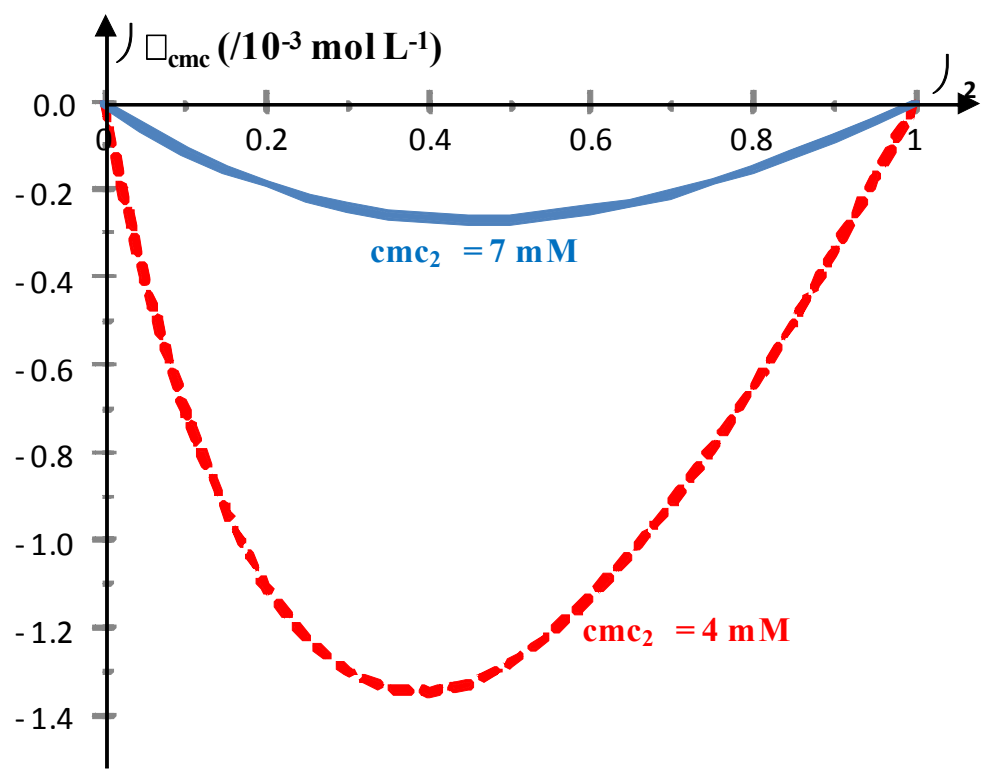

Figure 1: variation of the critical micellar concentration of mixture $\left(\Delta \theta_{\mathrm{cmc}}\right)$ with $\alpha_{2}$, for two critical micellar concentrations of 2 pure and $\mathrm{cmc}_{3}{ }^{\circ}=10 \mathrm{mM}$.

In all the situations, the Clint's relation suggests a negative critical micellar concentration of mixture without, obviously, synergistic effect since it was assumed that there is no interaction between the components of the mixture.

If for the nonionic surfactants the concept of ideal behaviour is correctly translated by the Clint relation, it is not systematically the same for mixtures implicating charged surfactants.

\subsubsection{Mixtures of charged and not charged surfactants}

As we noticed previously, the introduction of charged surfactants liable to dissociate into the mixture poses the problem of the enumeration of the species constituting the system.

One of the simplest ways to model this situation is not to seek to identify and to count the ions possibly released by the electrolyte, but to suppose that the ionic surfactant generates $r$ identical and indistinguishable particles. This assumption simplifies the situation since the 
medium is then constituted by $\mathrm{n}_{2}^{\mathrm{m}}$ moles of nonionic surfactants and $\mathrm{rn}_{3}^{\mathrm{m}}$ moles of particles coming from the ionic surfactant. The contents of the micellar pseudo-phase are

$\mathrm{N}=\mathrm{n}_{2}^{\mathrm{m}}+\mathrm{rn}_{3}^{\mathrm{m}}$

By supposing that surfactant $3,\left(\mathrm{M}^{+}, \mathrm{X}^{-}\right)$, is enough diluted in the bulk so the activity coefficients can be neglected, its chemical potential for an ideal solution can be written

$\mu_{3}=\mu_{3}^{\mathrm{m}}+\mathrm{RT} \ln \left(\mathrm{cmc} \frac{1-\alpha_{2}}{\mathrm{cmc}_{3}^{\mathrm{o}}}\right)^{2}=r \mu_{\mathrm{p}}=\mathrm{r} \mu_{\mathrm{p}}^{\mathrm{m}}+\mathrm{rRT} \ln \mathrm{x}_{3, \mathrm{r}}$

with

$\mu_{3}^{\mathrm{m}}=\mathrm{r} \mu_{\mathrm{p}}^{\mathrm{m}} \quad$ and $\quad \mathrm{x}_{3, \mathrm{r}}=\left(\frac{\mathrm{cmc}_{3}}{\mathrm{cmc}_{3}^{\mathrm{o}}}\right)^{2 / \mathrm{r}}$

$\mu_{\mathrm{p}}$ is the chemical potential of the particles and $\mu_{\mathrm{p}}^{\mathrm{m}}$ its standard chemical potential in their pure state. It is obviously a hypothetical state. $\mathrm{x}_{3, \mathrm{r}}$ is the molar fraction of the particles generated by the surfactant 3. Molar fractions of particles constituting the micellar system are linked to the stoichiometric molar fractions according to,

$$
\begin{aligned}
& \mathrm{x}_{2, \mathrm{r}}=\frac{\mathrm{n}_{2}^{\mathrm{m}}}{\mathrm{n}_{2}^{\mathrm{m}}+\mathrm{r} \mathrm{n}_{3}^{\mathrm{m}}}=\frac{\mathrm{x}_{2}}{\left.\mathrm{r}+\mathrm{x}_{2}(1-\mathrm{r})\right)} \\
& \mathrm{x}_{3, \mathrm{r}}=\frac{\mathrm{r} \mathrm{n}_{3}^{\mathrm{m}}}{\mathrm{n}_{2}^{\mathrm{m}}+\mathrm{r} \mathrm{n}_{3}^{\mathrm{m}}}=1-\mathrm{x}_{2, \mathrm{r}}=\frac{\mathrm{r}\left(1-\mathrm{x}_{2}\right)}{\left.\mathrm{r}+\mathrm{x}_{2}(1-\mathrm{r})\right)}
\end{aligned}
$$

The condition of ideality is then expressed by

$\mathrm{x}_{2, \mathrm{r}}+\mathrm{x}_{3, \mathrm{r}}=1=\mathrm{a}_{2}+\left(\mathrm{a}_{3}\right)^{1 / \mathrm{r}}=\frac{\alpha_{2}}{\mathrm{cmc}_{2}^{\mathrm{o}}} \mathrm{cmc}+\left(\frac{\left(1-\alpha_{2}\right)}{\mathrm{cmc}_{3}^{\mathrm{o}}} \mathrm{cmc}\right)^{2 / \mathrm{r}}$

A general condition of ideality is then established for mixtures of charged and non-charged surfactants, taking into account the number of particles supposed to be generated in the micellar pseudo-phase by the electrolyte MX. The previous relations can be generalized to the 
case where the surfactants 2 and 3 would be electrolytes likely to be dissociated in $r_{2}$ and $r_{3}$ particles, respectively,

$\mathrm{x}_{2, \mathrm{r}_{2}}+\mathrm{x}_{3, \mathrm{r}_{3}}=1=\left(\mathrm{a}_{2}\right)^{1 / \mathrm{r}_{2}}+\left(\mathrm{a}_{3}\right)^{1 / \mathrm{r}_{3}}=\left(\frac{\alpha_{2}}{\mathrm{cmc}_{2}^{0}} \mathrm{cmc}\right)^{2 / \mathrm{r}_{2}}+\left(\frac{\left(1-\alpha_{2}\right)}{\mathrm{cmc}_{3}^{\mathrm{o}}} \mathrm{cmc}\right)^{2 / \mathrm{r}_{3}}$

with

$\mathrm{x}_{2, \mathrm{r}_{2}}=\frac{\mathrm{r}_{2} \mathrm{n}_{2}^{\mathrm{m}}}{\mathrm{r}_{2} \mathrm{n}_{2}^{\mathrm{m}}+\mathrm{r}_{3} \mathrm{n}_{3}^{\mathrm{m}}}=\frac{\mathrm{r}_{2} \mathrm{x}_{2}}{\left.\mathrm{r}_{3}+\mathrm{x}_{2}\left(\mathrm{r}_{2}-\mathrm{r}_{3}\right)\right)}$

These relationships can be applied in several situations for mixtures of a non-charged surfactant, 2, and a charged surfactant, 3, for example $\mathrm{M}^{+}, \mathrm{X}^{-}$. In all the following cases, the ionic surfactant is supposed to be totally dissociated in solution and we will discuss the dissociation of surfactant 3 in the aggregates.

\subsubsection{The surfactant $M X$ is supposed not to be dissociated in the micelle, $r=1$}

It is generally under this shape that the ideality is considered in the framework of the application of the RST to mixtures of surfactants. By rewriting eq. 24, the condition of ideality is

$$
1=\frac{\alpha_{2}}{\mathrm{cmc}_{2}^{\mathrm{o}}} \mathrm{cmc}+\left(\frac{1-\alpha_{2}}{\mathrm{cmc}_{3}^{\mathrm{o}}} \mathrm{cmc}\right)^{2}
$$

This relation is different from the one proposed by Clint. The ideal behaviour for this kind of mixture can be easily simulated by resolving this quadratic equation. Several examples of simulation of $\Delta \theta_{\mathrm{cmc}}$ are plotted on figure 2 for different values of $\mathrm{cmc}_{2}^{\circ}$. Whereas the Clint's relation of ideality always envisages a negative mixture magnitude, it is noted that eq. 27 allows considering positive variations of critical micellar concentration of mixture when the cmc of the surfactants are close and negative variations when they are far. 


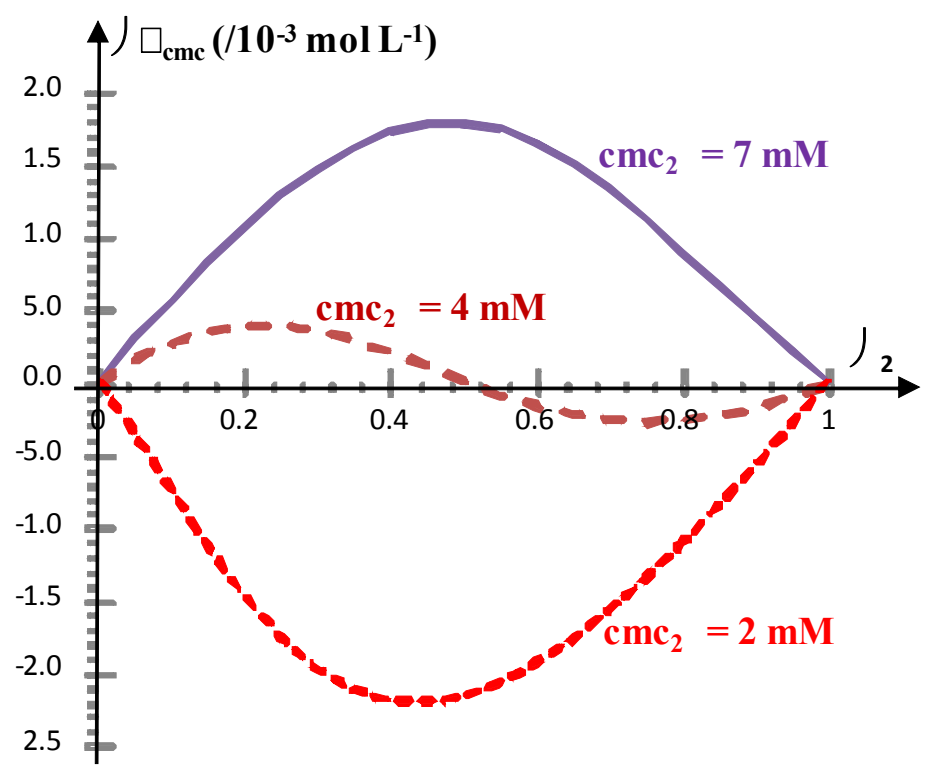

Figure 2: variation of the cmc of mixture with $\alpha_{2}$ for mixtures of charged and non-charged surfactants in the case of $\mathrm{r}=1$ and $\mathrm{cmc}_{3}{ }^{\circ}=10 \mathrm{mM}$. In this particular case, the ionic surfactant (3) is supposed to be totally associated in the micelle, but in solution the ionic surfactant is obviously totally dissociated.

We cannot talk about synergy in the case of $\mathrm{cmc}_{2}{ }^{\circ}=2 \mathrm{mM}$ and $\mathrm{cmc}_{3}{ }^{\circ}=10 \mathrm{mM}$, for which the curve presents a minimum, neither destabilization of the mixture in the case of $\mathrm{cmc}_{2}{ }^{\circ}=7 \mathrm{mM}$ and $\mathrm{cmc}_{3}{ }^{\circ}=10 \mathrm{mM}$ although the curve has a maximum. Indeed, in the considered situations, we must recall that there is no interaction between the components of the mixture.

\subsubsection{The surfactant $M X$ is supposed to be totally dissociated in the micelle, $r=2$}

In this case, eq. 24 becomes

$$
1=\frac{\alpha_{2}}{\mathrm{cmc}_{2}^{\mathrm{o}}} \mathrm{cmc}+\frac{\left(1-\alpha_{2}\right)}{\mathrm{cmc}_{3}^{\mathrm{o}}} \mathrm{cmc}
$$

The Clint's condition of ideality is then recovered. But it is necessary to have in mind that this equation is relative to compositions of micelle which involve a total dissociation of the 
electrolyte into two identical particles. Molar fractions of the components in the mixture differ from the stoichiometric molar fractions of $x_{2}$ and $x_{3}$. They are such as

$$
\begin{aligned}
& \mathrm{x}_{2,2}=\frac{\mathrm{x}_{2}}{2-\mathrm{x}_{2}} \\
& \mathrm{x}_{3,2}=\frac{2\left(1-\mathrm{x}_{2}\right)}{2-\mathrm{x}_{2}}
\end{aligned}
$$

This remark is important when the RST is used to determine the composition of surfactants mixtures.

In the two examined cases, values of $r$ are integers, but, a priori, there is no reason to suppose it.

\subsubsection{The surfactant $M X$ is supposed to be partly dissociated in the micelle $(1<\mathrm{r}<2)$}

Figure 3 showed variations of critical micellar concentrations of the mixture with $\alpha_{2}$ calculated from eq. 24 for the same values of $\mathrm{cmc}^{\circ}\left(\mathrm{cmc}_{2}^{\circ}=4 \mathrm{mM}\right.$ and $\left.\mathrm{cmc}_{3}^{\circ}=10 \mathrm{mM}\right)$ but with different values of r. Eq. 24 has been resolved by iteration (using the solver of the software Excel) for each value of $\alpha_{2}$.

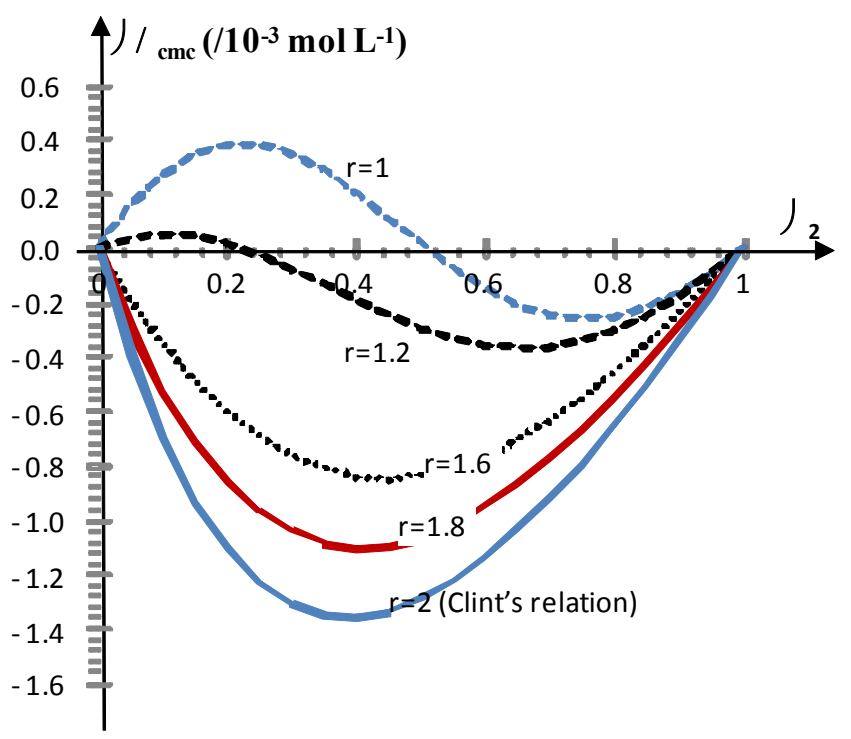


Figure 3: variation of the cmc of the mixture against $\alpha_{2}$ for mixtures of charged and noncharged surfactants with $\mathrm{cmc}_{2}{ }^{\circ}=4 \mathrm{mM}, \mathrm{cmc}_{3}{ }^{\circ}=10 \mathrm{mM}$ and different values of $\mathrm{r}$. $\mathrm{r}$ is the number of particles generated by the ionic surfactant into the micelle.

As is shown on figure 3, different ideal behaviours can be defined depending on the value of

r. Each of them can be used as reference behaviour to describe the experimental results.

\subsection{Case of micellization in the presence of supporting electrolyte}

In the presence of a supporting electrolyte, having the same counterion that the charged surfactant, a reasoning similar to the previous one can be carried out by writing that the activity of the charged species is

$$
\mathrm{a}_{3}^{\mathrm{m}}=\frac{\mathrm{a}_{3}^{\mathrm{b}}}{\mathrm{a}_{3}^{\mathrm{b}, \mathrm{o}}}=\frac{\mathrm{a}_{\mathrm{M}^{+}}^{\mathrm{b}} \mathrm{a}_{\mathrm{X}^{-}}^{\mathrm{b}}}{\mathrm{a}_{\mathrm{M}^{+}}^{\mathrm{b}, \mathrm{a}} \mathrm{a}_{\mathrm{X}^{-}}^{\mathrm{b}}} \approx \operatorname{cmc} \frac{1-\alpha_{2}}{\mathrm{cmc}_{3}^{\mathrm{o}}}
$$

Using the same definitions as in the previous case, one can write for an ideal solution

$$
\begin{aligned}
& \mathrm{x}_{2, \mathrm{r}}=\frac{1-\mathrm{x}_{3}}{1+\mathrm{x}_{3}(\mathrm{r}-1)}=\frac{\mathrm{cmc}_{2}}{\mathrm{cmc}_{2}^{\mathrm{o}}} \\
& \mathrm{x}_{3, \mathrm{r}}=\left(\frac{\mathrm{cmc}_{3}}{\mathrm{cmc}_{3}^{\mathrm{o}}}\right)^{1 / \mathrm{r}}
\end{aligned}
$$

The condition of ideality is then expressed by

$$
\mathrm{x}_{2, \mathrm{r}}+\mathrm{x}_{3, \mathrm{r}}=1=\frac{\mathrm{cmc}_{2}}{\mathrm{cmc}_{2}^{\mathrm{o}}}+\left(\frac{\mathrm{cmc}_{3}}{\mathrm{cmc}_{3}^{\mathrm{o}}}\right)^{1 / \mathrm{r}}=\frac{\alpha_{2}}{\mathrm{cmc}_{2}^{\mathrm{o}}} \mathrm{cmc}+\left(\frac{1-\alpha_{2}}{\mathrm{cmc}_{3}^{\mathrm{o}}} \mathrm{cmc}\right)^{1 / \mathrm{r}}
$$

As previously, several situations can be considered depending on the values of $r$. When $r=1$, the Clint's relation is recovered. Critical micelle concentrations of mixture for different values of $r$ are plotted on figure 4. 


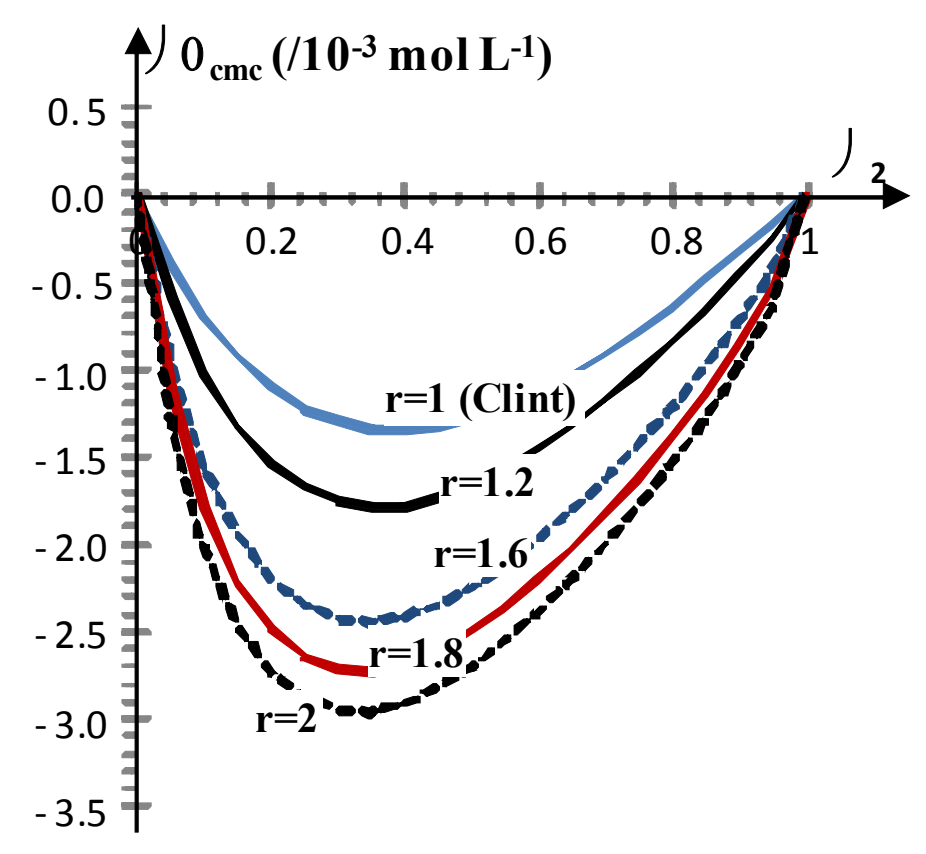

Figure 4: Variation of the cmc of the mixture with $\alpha_{2}$ for mixtures of non-charged and charged surfactants (with $\mathrm{cmc}_{2}{ }^{\circ}=4 \mathrm{mM}, \mathrm{cmc}_{3}{ }^{\circ}=10 \mathrm{mM}$ ) in the presence of a supporting electrolyte, for various values of $r$.

Contrary to the previous case, in the presence of a support electrolyte, all the curves show a minimum. The behaviours of some mixtures can be described by this kind of ideal behaviour. As an illustration (figure 5), we applied this approach to the experimental values of DTABrBrij mixtures in saline medium $\left(0.3 \mathrm{~mol} \mathrm{~L}^{-1} \mathrm{NaBr}\right)$ we had previously published [2]. At that time, we had concluded that their behaviour deviated a little from the ideal solutions by supposing that DTABr did not dissociate $(r=1)$. In fact, we note that the variations of $\mathrm{cmc}$ of the mixtures are well described by supposing an ideal model with $r=1.4$ (see figure 5). 


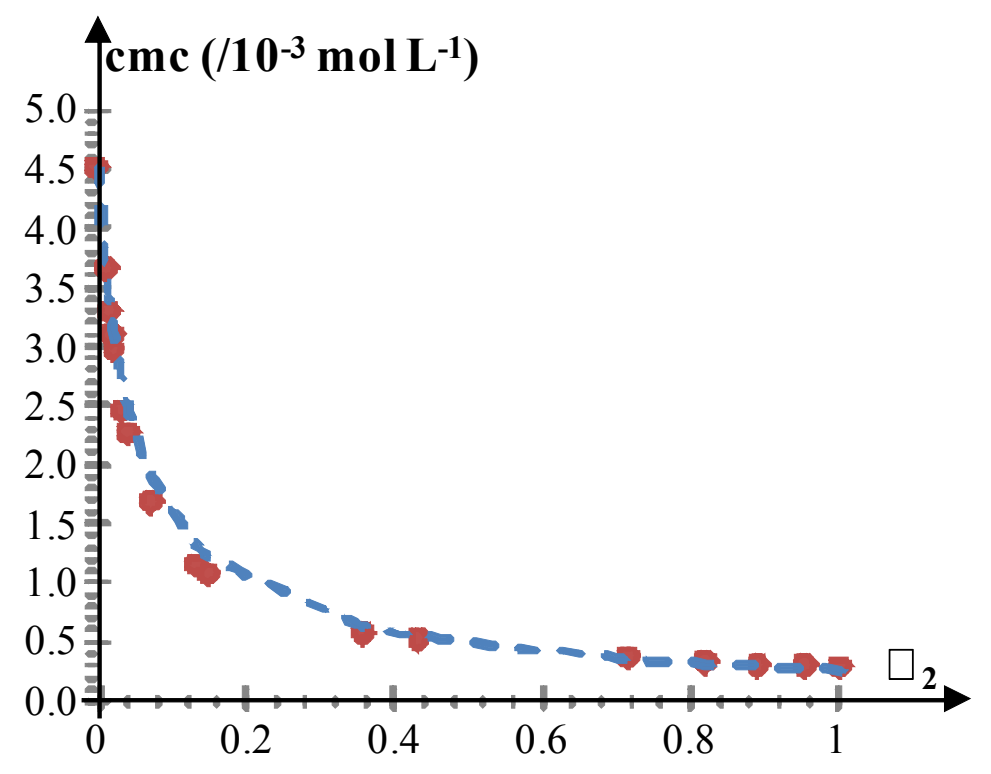

Figure 5: variation of the cmc with $\alpha_{2}$ for DTABr-Brij 35 mixtures in $0.3 \mathrm{~mol} \mathrm{~L}^{-1} \mathrm{NaBr}$ aqueous solution. Experimental data correspond to the dark points. Dashed line represents the calculated value with $\mathrm{r}=1.4$.

In conclusion of this thought on the ideal mixtures concerning mixed micelles (formalized in a very general way by eqs. 25 and 32 for charged surfactants, 1:1 electrolytes) we note that there is an infinity of behaviours of reference according to the way in which the dissociation of the surfactants in the pseudo-phase are considered.

This point is very important because it directly involves in the exploitation of the Regular Solution Theory (RST).

\section{Discussion: for a suitable use of the Regular Solution Theory (RST)}

As for ideal mixtures, Regular Solution Theory supposes a random distribution of the mixture components but with a possible interaction between them which results in an enthalpic effect. In the majority of works on this subject, the behaviour of a mixture of micellized surfactants, whatever the nature of the mixture components, is supposed to follow the relation 


$$
\frac{1}{\mathrm{cmc}}=\frac{\alpha_{2}}{\gamma_{2} \mathrm{cmc}_{2}^{\mathrm{o}}}+\frac{1-\alpha_{2}}{\gamma_{3} \mathrm{cmc}_{3}^{\mathrm{o}}}
$$

$\gamma_{2}$ et $\gamma_{3}$ are the activity coefficients of 2 and 3, referred to «ideal behaviour». They are linked to the composition of the mixture by the coefficient of interaction $\beta$, such as,

$$
\begin{aligned}
& \ln \gamma_{2}=-\beta\left(1-x_{2}\right)^{2} \\
& \ln \gamma_{3}=-\beta x_{2}{ }^{2}
\end{aligned}
$$

This shape of equation allows accounting for the presence of a minimum in the curve of variation of the cmc with $\alpha_{2}$ for numerous mixtures of ionic and nonionic surfactants. This effect of synergy (which is generally interpreted as a stabilization of the micelle) was largely discussed in the literature [19-21].

For mixtures of nonionic surfactants, eq. 33 is valid. The ideal behaviour is that described by the Clint's relation, by taking into account the (stoichiometric) molar fractions of the two components of the mixture.

On the other hand, for the mixtures of ionic and nonionic uncharged surfactants, eq. 33 can make no sense. To define an activity coefficient, it is indispensable to adopt an ideal behaviour of reference, i.e. to count the particles constituting the system.

In what follows, we will not take part on the relevance to use this model which was amply commented [22, 23], but we will show how this one should be used to fulfill the requirements of thermodynamics.

Consider a mixture between a nonionic surfactant 2 and an ionic surfactant 3 . The activity of surfactant 2 is written within the framework of the regular solution theory by considering a dissociation of 3 ,

$$
\ln \mathrm{a}_{2}=\ln \mathrm{x}_{2, \mathrm{r}}+\ln \gamma_{2}=\ln \mathrm{x}_{2, \mathrm{r}}-\beta\left(1-\mathrm{x}_{2, \mathrm{r}}\right)^{2}
$$

$\gamma_{2}$ is a term which characterizes the deviation between the behaviour of component 2 in the real mixture and this in the ideal mixture in which component 3 is supposed to generate $r$ 
particles $\left(\mathrm{x}_{2, \mathrm{r}}\right) . \beta$ is the term of reciprocal interaction. The corresponding expression of $\mathrm{a}_{3}$ can be determined by applying the Gibbs-Duhem relation to the pseudo-phase

$$
\mathrm{n}_{2}^{\mathrm{m}} \mathrm{d} \mu_{2}+\mathrm{n}_{3}^{\mathrm{m}} \mathrm{d} \mu_{3}=0
$$

what leads, by dividing by the total number of particles $\mathrm{N}$ and expanding the expression of the chemical potentials, to the following equality

$$
\mathrm{x}_{2, \mathrm{r}} \mathrm{d} \ln \mathrm{a}_{2}+\frac{\left(1-\mathrm{x}_{2, \mathrm{r}}\right)}{\mathrm{r}} \mathrm{d} \ln \mathrm{a}_{3}=0
$$

The expression of the activity of 3 with the composition of the system is then

$$
\mathrm{d} \ln \mathrm{a}_{3}=-\mathrm{r} \frac{\mathrm{x}_{2, \mathrm{r}}}{1-\mathrm{x}_{2, \mathrm{r}}} \mathrm{d} \ln \mathrm{x}_{2, \mathrm{r}}+\mathrm{r} \frac{\mathrm{x}_{2, \mathrm{r}}}{1-\mathrm{x}_{2, \mathrm{r}}} \beta \mathrm{d}\left(1-\mathrm{x}_{2, \mathrm{r}}\right)^{2}
$$

And then,

$$
\mathrm{d} \ln \mathrm{a}_{3}=-\mathrm{r} \frac{\mathrm{dx} \mathrm{x}_{2, \mathrm{r}}}{1-\mathrm{x}_{2, \mathrm{r}}}-2 \beta \mathrm{rx}_{2, \mathrm{r}} \mathrm{dx}_{2, \mathrm{r}}
$$

This equation can be integrated between $\left(\mathrm{x}_{2, \mathrm{r}}=0, \mathrm{a}_{3}=1\right)$ and $\left(\mathrm{x}_{2, \mathrm{r}}, \mathrm{a}_{3}\right)$

$$
\ln \left(\mathrm{a}_{3}\right)^{1 / \mathrm{r}}=\ln \left(1-\mathrm{x}_{2, \mathrm{r}}\right)-\beta\left(\mathrm{x}_{2, \mathrm{r}}\right)^{2}
$$

In the framework of the RST, the critical micellar concentrations of the mixtures of charged and uncharged surfactants are then linked by these simultaneous relations

$$
\begin{aligned}
& \ln \left(\frac{\mathrm{cmc}}{\mathrm{x}_{2, \mathrm{r}}} \frac{\alpha_{2}}{\mathrm{cmc}_{2}^{\mathrm{o}}}\right)=-\beta\left(1-\mathrm{x}_{2, \mathrm{r}}\right)^{2} \\
& \ln \frac{1}{\left(1-\mathrm{x}_{2, \mathrm{r}}\right)}\left(\mathrm{cmc} \frac{1-\alpha_{2}}{\mathrm{cmc}_{3}^{\mathrm{o}}}\right)^{2 / \mathrm{r}}=-\beta\left(\mathrm{x}_{2, \mathrm{r}}\right)^{2}
\end{aligned}
$$

From these two relations, a rule of variation of the critical micellar concentration is established according to the composition of the mixture $\alpha_{2}$

$$
1=x_{2, r}+x_{3, r}=c m c \frac{\alpha_{2}}{c m c_{2}^{0}} e^{\beta\left(1-x_{2, r}\right)^{2}}+\left(c m c \frac{1-\alpha_{2}}{c m c_{3}^{o}}\right)^{2 / r} e^{\beta\left(x_{2, r}\right)^{2}}
$$

This relation can be then written 
$1=\frac{1}{\gamma_{2}} \mathrm{cmc} \frac{\alpha_{2}}{\mathrm{cmc}_{2}^{\mathrm{o}}}+\frac{1}{\gamma_{3}}\left(\mathrm{cmc} \frac{1-\alpha_{2}}{\mathrm{cmc}_{3}^{\mathrm{o}}}\right)^{2 / \mathrm{r}}$

with $\frac{1}{\gamma_{2}}=\mathrm{e}^{\beta\left(1-\mathrm{x}_{2, \mathrm{r}}\right)^{2}}$ and $\frac{1}{\gamma_{3}}=\mathrm{e}^{\beta\left(\mathrm{x}_{2, \mathrm{r}}\right)^{2}}$

As we can see, the values of the activity coefficients depend on the values adopted for $r$. the consistency of eq. 43 can be checked by taking $\beta=0$ then $\gamma_{2}=\gamma_{3}=1$. We then recover eq. 24 which defines the ideal behaviours of charged and uncharged micelles.

In the presence of support electrolyte, the rule of variation of the critical micellar concentration according to the composition of the mixture $\alpha_{2}$ is written as

$1=x_{2, r}+x_{3, r}=c m c \frac{\alpha_{2}}{c m c_{2}^{0}} e^{\beta\left(1-x_{2, r}\right)^{2}}+\left(\operatorname{cmc} \frac{1-\alpha_{2}}{c m c_{3}^{o}}\right)^{1 / r} e^{\beta\left(x_{2, r}\right)^{2}}$

In order to illustrate eq. 43 , the variations of the simulated $\mathrm{cmc}$ for a mixture of ionic surfactant $\left(\mathrm{cmc}_{2}^{\circ}=4 \mathrm{mM}\right)$ and nonionic surfactant $\left(\mathrm{cmc}_{3}^{\circ}=10 \mathrm{mM}\right)$ are plotted against $\alpha_{2}$, by taking a constant value $\beta=4$. Eq. 43 was solved using an iterative approach. As comparison the curves corresponding to the ideal behaviours for $\mathrm{r}=1$ and $\mathrm{r}=2$ are also plotted.

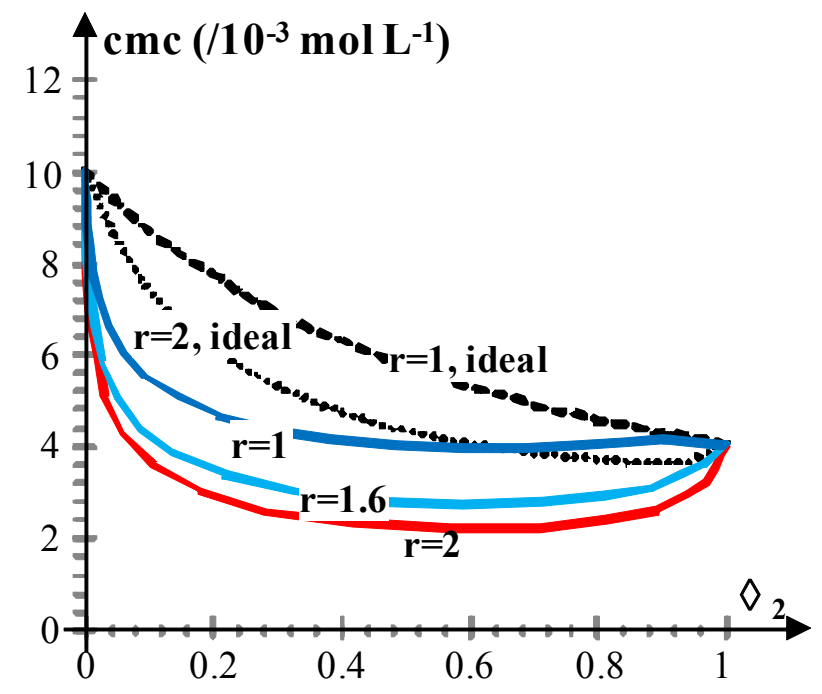

Figure 6: ideal behaviours ( $\mathrm{r}=1$ and $\mathrm{r}=2)$ and behaviours described from the RST for $\beta=4$ with $\mathrm{r}=1,1.6$ and 2 (solid lines). The $\mathrm{cmc}$ are equal to $4 \mathrm{mM}$ for the nonionic surfactant and 10 $\mathrm{mM}$ for the ionic surfactant. 
As is shown on figure 6 , for the same value of $\beta$, the differences between the ideal behaviours and those corresponding to the RST are more important in the case of $r=2$ than for $r=1$. The result is that according to the adopted value of $r$, one will have different conclusions on the importance of the interactions between the components of the mixture.

To illustrate this conclusion we exploited, in a completely different way than the authors, the results on the mixtures of sodium dodecylsulfate and dodecyldimethylamine N-oxide in aqueous solutions, without support electrolyte, presented by Varade et al. [24] (figure 7). These surfactants are supposed to strongly interact by electrostatic forces.

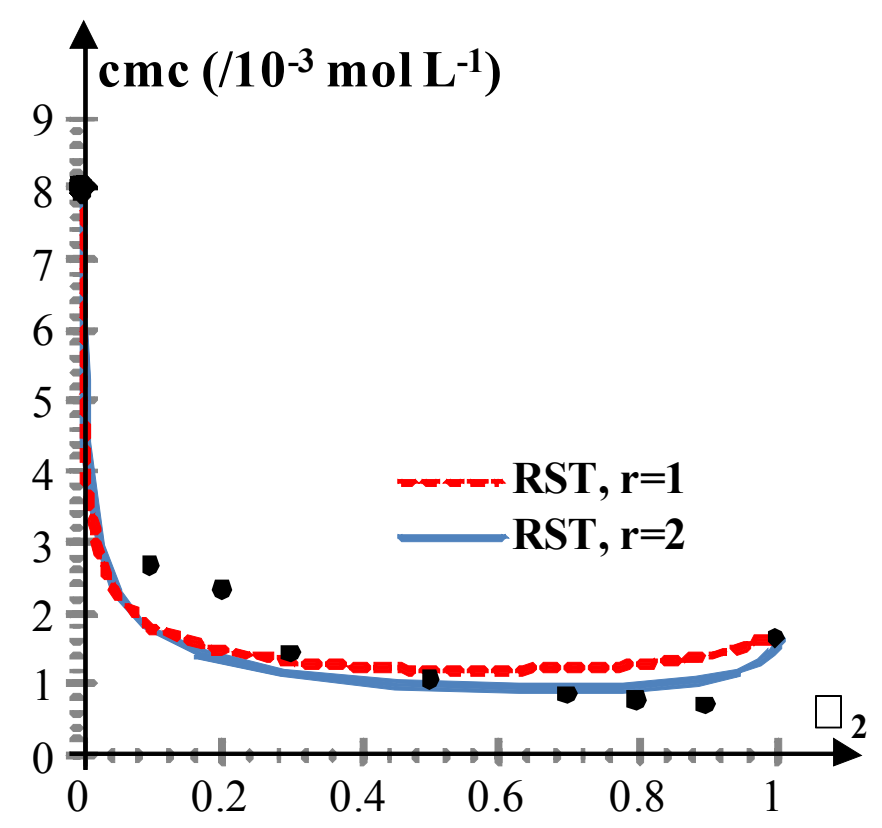

Figure 7: mixture of dodecylsulfate and dodecyldimethylamine $\mathrm{N}$-oxide in water (data from ref. 24, dark points). RST models with $r=1$ and $\beta=8$ (dashed line), $r=2$ and $\beta=5$ (solid line).

It is noteworthy that the two RST models with $r=1$ and $r=2$ can fairly account for the experimental results with constant values of $\beta$. But for $r=1$, it is necessary to take a value of $\beta=8$, whereas for $r=2$, the value of $\beta$ is only of 5 . The difference between the ideal behaviour 
and RST is weaker in the case of $r=2$. This kind of results poses a problem of interpretation of the experimental data in terms of interaction. What to conclude in absolute way on the importance of the interactions between the two components of the mixture, whereas the value of the parameter $\beta$ varies with the way how the solution is considered?

One of the ways to answer this question is undoubtedly to remember that in the RST model, the activity coefficients are directly related to heats of mixture.

Several studies showed the inadequacy between the conclusions of the RST and calorimetric measurements for some mixtures between charged and uncharged surfactants [25]. Other measurements allow, on the other hand, confirming the ideal behaviour of the mixtures of nonionic surfactants [26].

Calorimetry constitutes an interesting way to characterize the behaviour of mixed micelles $[27,28]$. Especially, in the case of an interpretation of the measurements by means of the RST, calorimetry can, maybe, allow determining the best value of $r$ to take into account. Thus, as for the solvent mixtures, the knowledge of the enthalpy of mixture is essential for the comprehension of the systems [29-31].

The study we presented can be, obviously, widened to charged surfactant mixtures, by supposing that each compound 2 and 3 is likely to generate $r_{2}$ and $r_{3}$ particles respectively.

\section{Conclusion}

The adaptation of the usual thermodynamic models to the mixed micellar phases requires great precautions because possible dissociation of the components of the mixture has to be considered in the bulk as well in micelle.

Therefore, Clint's relation characterizes an ideal behaviour only in some particular cases.

This study on the ideal solutions could be completely formal and of secondary importance if it did not permit to discuss the conditions of the RST applications. The theory of regular 
solutions expresses the variations of the activity coefficients of the mixture's components according to their molar fractions. Consequently, the number of particles supposed to be present in the mixed micellar phase must be specified.

We have to admit that the majority of the studies in the literature on the mixtures of charged and non-charged surfactants applying the RST use erroneous approaches, especially, in aqueous solutions without support electrolyte. Indeed,

- either they suppose that Clint's relation applies, and then, $r$ must be equal to 2 . That implies that the given molar fractions are not the stoichiometric ones $\left(\mathrm{x}_{2}, \mathrm{x}_{3}\right)$, but those which take into account the total dissociation of the ionic surfactants $\left(\mathrm{x}_{2, \mathrm{r}}\right.$ and $\left.\mathrm{x}_{3, \mathrm{r}}\right)$. In such a situation, the interpretation of the values of $\beta$ must be considered between two particles for ionic surfactant and one particle for the molecular species which compose the pseudo-phase.

- or, they suppose that the charged surfactants are not dissociated. Clint's relation does not apply, just as the classical equations of RST. In particular, the relation of consistency should be written as

$$
\ln \left(\frac{\mathrm{cmc}}{\mathrm{x}_{2}} \frac{\alpha_{2}}{\mathrm{cmc}_{2}^{\mathrm{o}}}\right)=\frac{\left(1-\mathrm{x}_{2}\right)^{2}}{\left(\mathrm{x}_{2}\right)^{2}} \ln \left(\frac{1}{\left(1-\mathrm{x}_{2}\right)}\left(\mathrm{cmc} \frac{1-\alpha_{2}}{\mathrm{cmc}_{3}^{\mathrm{o}}}\right)^{2}\right)
$$

It is besides this relation which used Peyre [32] in a study on mixtures of surfactants with hydrogenated and fluorinated chains.

On the other hand, when the studies are undertaken in the presence of a support electrolyte, the assumption $\mathrm{r}=1$ leads to an ideal behaviour according to Clint and an application according to the usual relations used for RST. The only problem is then, in some publications, the comparison of the behaviours between aqueous and saline solutions from the same equations and values of $r$.

In conclusion, it seems to us that the interpretation of numerous experimental results of the literature would require to be reconsidered. 
To finish, it should be noted that other models of solution, as BET [33, 34], do not require formally adopting an ideal model of reference because they directly treat the activities of the species in the mixture and not the activity coefficients. The BET model is generally used to account for the properties of concentrated aqueous salt mixtures. We proposed in a recent work to apply it to mixtures of charged and non-charged surfactants [35]. 


\section{References}

[1] E. A. Guggenheim, Mixtures: the theory of the equilibrium properties of some simple classes of mixtures solutions and alloys. Oxford University Press ed.; 1952,

[2] J. L. Palous, M. Turmine, P. Letellier, J. Phys. Chem. B, 102 (1998) 5886-5890.

[3] P. Letellier, A. Mayaffre, M. Turmine, J. Colloid Interface Sci., 327 (2008) 186-190.

[4] P. M. Holland, D. N. Rubingh, J. Phys. Chem., 87 (1983) 1984-1990.

[5] J. H. Clint, J. Chem. Soc., Faraday trans. I, 71 (1975) 1327-1334.

[6] R. Defay, Etude Thermodynamique de la tension superficielle. Gauthier-Villars \& Cie: Paris, 1934,

[7] P. Letellier, A. Mayaffre, M. Turmine, J. Colloid Interface Sci., 321 (2008) 195-204.

[8] M. Turmine, A. Mayaffre, P. Letellier, J. Phys. Chem. B, 108 (2004) 18980-18987.

[9] S. Puvvada, D. Blankschtein, J. Chem. Phys., 92 (1990) 3710-3724.

[10] S. Puvvada, D. Blankschtein, J. Phys. Chem., 96 (1992) 5567-5579.

[11] S. Puvvada, D. Blankschtein, J. Phys. Chem., 96 (1992) 5579-5592.

[12] A. Shiloach, D. Blankschtein, Langmuir, 14 (1998) 7166-7182.

[13] A. Shiloach, D. Blankschtein, Langmuir, 14 (1998) 1618-1636.

[14] A. Goldsipe, D. Blankschtein, Langmuir, 23 (2007) 5942-5952.

[15] B. C. Stephenson, A. Goldsipe, K. J. Beers, D. Blankschtein, J. Phys. Chem. B, 111 (2007) 1045-1062.

[16] E. A. Guggenheim, Thermodynamique. Dunod ed.; Paris, 1965.

[17] D. G. Hall, R. W. Huddleston, Colloids and Surfaces, 13 (1985) 209-219.

[18] J. F. Rathman, J. F. Scamehorn, Langmuir, 2 (1986) 354-361.

[19] M. Bergstrom, P. Jonsson, M. Persson, J. C. Eriksson, Langmuir, 19 (2003) 1071910725. 
[20] P. C. Schulz, J. L. Rodriguez, R. M. Minardi, M. B. Sierra, M. A. Morini, Journal of Colloid and Interface Science, 303 (2006) 264-271.

[21] Z. W. Wang, H. X. Yu, Z. N. Wang, G. Z. Li, J. Dispers. Sci. Technol., 27 (2006) 723726.

[22] H. Hoffmann, G. Possnecker, Langmuir, 10 (1994) 381-389.

[23] J. D. Hines, Curr. Opin. Colloid Interface Sci., 6 (2001) 350-356.

[24] D. Varade, T. Joshi, V. K. Aswal, P. S. Goyal, P. A. Hassan, P. Bahadur, Colloid Surf. A, 259 (2005) 103-109.

[25] M. J. Hey, J. W. Mactaggart, C. H. Rochester, J. Chem. Soc., Faraday trans. I, 81 (1985) 207-213.

[26] A. Ohta, S. Miyagishi, M. Aratono, J. Phys. Chem. B, 105 (2001) 2826-2832.

[27] T. P. Golub, A. de Keizer, Langmuir, 20 (2004) 9506-9512.

[28] J. F. Rathman, J. F. Scamehorn, Langmuir, 4 (1988) 474-481.

[29] R. DeLisi, A. Inglese, S. Milioto, A. Pellerito, Fluid Phase Equilib., 126 (1996) 273-287.

[30] R. DeLisi, A. Inglese, S. Milioto, A. Pellerito, J. Colloid Interface Sci., 180 (1996) 174187.

[31] R. Crisantino, R. Delisi, S. Milioto, J. Solut. Chem., 23 (1994) 639-662.

[32] V. Peyre, S. Patil, G. Durand, B. Pucci, Langmuir, 23 (2007) 11465-11474.

[33] S. Brunauer, P. H. Emmett, E. Teller, J. Am. Chem. Soc., 60 (1938) 309-319.

[34] R. H. Stokes, R. A. Robinson, J. Am. Chem. Soc., 70 (1948) 1870-1878.

[35] P. Letellier, A. Mayaffre, M. Turmine, J. Colloid Interface Sci., 337 (2009) 234-239. 


\section{Figure Captions}

Figure 1: variation of the critical micellar concentration of mixture $\left(\Delta \theta_{\mathrm{cmc}}\right)$ with $\alpha_{2}$, for two critical micellar concentrations of 2 pure and $\mathrm{cmc}_{3}{ }^{\circ}=10 \mathrm{mM}$.

Figure 2: variation of the cmc of mixture with $\alpha_{2}$ for mixtures of charged and non-charged surfactants in the case of $\mathrm{r}=1$ and $\mathrm{cmc}_{3}{ }^{\circ}=10 \mathrm{mM}$. In this particular case, the ionic surfactant (3) is supposed to be totally associated in the micelle, but in solution the ionic surfactant is obviously totally dissociated.

Figure 3: variation of the cmc of the mixture against $\alpha_{2}$ for mixtures of charged and noncharged surfactants with $\mathrm{cmc}_{2}{ }^{\circ}=4 \mathrm{mM}, \mathrm{cmc}_{3}{ }^{\circ}=10 \mathrm{mM}$ and different values of $\mathrm{r}$. $\mathrm{r}$ is the number of particles generated by the ionic surfactant into the micelle.

Figure 4: Variation of the cmc of the mixture with $\alpha_{2}$ for mixtures of non-charged and charged surfactants (with $\mathrm{cmc}_{2}{ }^{\circ}=4 \mathrm{mM}, \mathrm{cmc}_{3}{ }^{\circ}=10 \mathrm{mM}$ ) in the presence of a supporting electrolyte, for various values of $r$.

Figure 5: variation of the cmc with $\alpha_{2}$ for DTABr-Brij 35 mixtures in $0.3 \mathrm{~mol} \mathrm{~L}^{-1} \mathrm{NaBr}$ aqueous solution. Experimental data correspond to the dark points. Open squares represent the calculated value with $\mathrm{r}=1.4$.

Figure 6: ideal behaviours $(r=1$ and $r=2)$ and behaviours described from the RST for $\beta=4$ with $\mathrm{r}=1,1.6$ and 2 (solid lines). The cmc are equal to $4 \mathrm{mM}$ for the nonionic surfactant and 10 $\mathrm{mM}$ for the ionic surfactant. 
Figure 7: mixture of dodecylsulfate and dodecyldimethylamine N-oxide in water (data from ref. 24, dark points). RST models with $r=1$ and $\beta=8$ (dashed line), $r=2$ and $\beta=5$ (solid line). 